doi: $10.15407 /$ ujpe60.07.0593

V.I. BORYSYUK,${ }^{1}$ V.M. YASHCHUK, ${ }^{1}$ A.P. NAUMENKO,${ }^{1}$ A.V. STANOVA, ${ }^{1}$ V.G. GERASOVA, ${ }^{2}$ A.O. GERASOV ${ }^{3}$ YU.P. KOVTUN,${ }^{3}$ M.P. SHANDURA,${ }^{3}$ O.D. KACHKOVSKY ${ }^{3}$

${ }^{1}$ Taras Shevchenko National University of Kyiv, Faculty of Physics (64/13, Volodymyrs'ka Str., Kyiv 01601, Ukraine)

2 Taras Shevchenko National University of Kyiv, Faculty of Chemistry (64/13, Volodymyrs'ka Str., Kyiv 01601, Ukraine)

${ }^{3}$ Institute of Organic Chemistry, Nat. Acad. of Sci. of Ukraine (5, Murmans'ka Str., Kyiv 03660, Ukraine)

\title{
INFLUENCE OF SURPLUS NEGATIVE CHARGE ON ABSORPTION AND FLUORESCENCE EXCITATION SPECTRA OF ASYMMETRIC POLYMETHINE DYES
}

PACS 42.70.-a, 42.70.Jk

\section{Introduction}

One of the major problems in nanoelectronics is the design and synthesis of molecular systems with predictable current-voltage characteristics (CVC). For example, a model of molecular diode as a system of two non-conjugated $\pi$-electron systems with a given hierarchy of energy levels was proposed in [1]. The diode nature of the CVC of this system was confirmed

(C) V.I. BORYSYUK, V.M. YASHCHUK,

A.P. NAUMENKO, A.V. STANOVA, V.G. GERASOVA,

A.O. GERASOV, YU.P. KOVTUN, M.P. SHANDURA,

O.D. KACHKOVSKY, 2015

ISSN 2071-0194. Ukr. J. Phys. 2015. Vol. 60, No. 7
The combined spectral and quantum-chemical investigations of the vinylog series of the asymmetric anionic polymethine dyes, derivatives of aminocoumarin, as well as the related symmetric dyes, are fulfilled. The charge injection to these types of dyes leads to the essential to asymmetric dyes leads to a slight decrease of the spectral effect of the chromophore ine influence of the asymmetry manifests itself in a positive deviation in the abin the anisotropy of the fluorescence excitation spectra of asymmetric dyes. It is found that the lengthening of the chromophore is accompanied by an increase of the deviation of the first electron transition and, in contrast, by a decrease of the deviation of the second transition. The obtained results may be used in the design of molecular systems with prognosed current-voltage

Ke ywords: anion polymethine dyes, absorption spectra, fluorescence spectra, fluorescence excitation anisotropy spectra, quantum-chemical calculations, current-voltage characteristic.

experimentally with the use of two independent methods. For the successful execution of such works, it is necessary to know the features of the electric current through a molecule. For example, what happens in a molecular system with the appearance of an excess electric charge (by injecting electrons or holes from the electrode)? In our opinion, these processes can be modeled, by using anionic or cationic dyes and by comparing their properties with the properties of the corresponding neutral molecules.

Asymmetric polymethine dyes continue to be widely used, in parallel with the corresponding symmetric dyes, in numerous applications due to their 


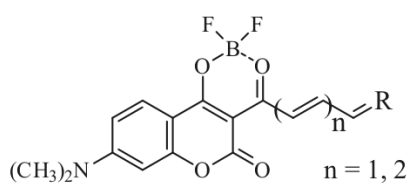

$$
\begin{array}{r}
\mathbf{R}_{\mathrm{n}}^{-}=\mathrm{R} \\
\mathrm{n}=1,2
\end{array}
$$

1

2

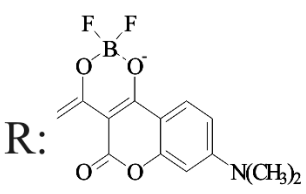

G

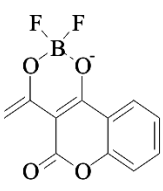

G-H

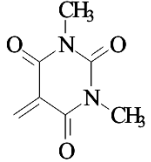

Bar<smiles>C=C(N)N</smiles>

Malo
Fig. 1. Chemical formula of the dyes under study

unique electronic and spectral properties, which form a basis for the design of new efficient materials related to the light conversion [2-5]. In addition, the symmetric and asymmetric polymethine molecules remain convenient objects for developing the new theoretical conceptions and quantum-chemical models [6-9]. So, the numeral investigations had shown that going from symmetric dyes to their asymmetric derivatives causes significant changes of the spectral characteristics caused by changes in the charge distribution and in the equilibrium molecular geometry in the polymethine chromophore $[2,3,5,10-12]$.

Recently, we have studied, in details, the influence of the asymmetry on the electron structure in the ground and excited states, as well as on the electron transitions in the cationic polymethine dyes with both typical cyanine terminal groups (indolenine and its analogs, quinoline and $p$-dimethylaminophenyl) [13] and specific terminal residues giving the local levels (2-azaazulene and pyrane) [14,15]. The study of spectra and the quantum-chemical modeling have shown that the first two electron transitions in the symmetric and asymmetric cationic dyes involve the highest occupied molecular orbitals (HOMO and HOMO-1) and the lowest unoccupied molecular orbital (LUMO). In the anionic polymethine dyes, in contrast, the first two excited states involve two lowest vacant levels and the highest occupied level. In our previous papers $[16,17]$, we have shown that this difference between cationic and anionic polymethine dyes is related to the existence of the specific level of a charge or the so-called solitonic level and, hence, to a shift of the energy gap down or up at the injection of a charge of the opposite sign (hole or electron). It was established that there is the practically mirror correspondence of the relative dispositions of the solitonic and terminal levels in the cationic cyanine dyes and related anionic dyes.

It can expected that the corresponding mirror image should remain in the asymmetric anionic dyes. In this paper, we present the results of spectral and quantum-chemical investigations of the asymmetric anionic dyes derivatives $\mathbf{1}$ aminocoumarin and the corresponding symmetric dyes $\mathbf{2}$ shown in Fig. 1.

\section{Measurements and Quantum-Chemical Calculations}

The synthesis of the compounds $\mathbf{1}, \mathbf{2}, n=1,2$ was described earlier [17].

The UV-Vis absorption spectra were recorded on a Shimadzu UV-3100 spectrophotometer in toluene, acetonitrile, and ethylene glycol (spectral grade).

The fluorescence excitation anisotropy measurements are performed using a CM 2203 spectrofluorimeter (Solar, Belarus) in viscous solutions to reduce the rotational reorientation and at low concentrations $\left(C=10^{-6} \mathrm{M}\right)$ to avoid the re-absorption of the fluorescence. The anisotropy is recorded by a standard procedure [19].

The quantum-chemical calculation. The equilibrium geometry of dye molecules in the ground state was optimized by the non-empirical DFT/631G*/B3LYP methods (package Gaussian 03 [20]); the electron transition characteristics were calculated by the TD DFT method. There is no perfect coinciding of the calculated and experimental data; however, it is enough to analyze correctly the nature of the electron transitions.

\section{Results and Discussion}

Many of the specific spectral effects observed for the ions of $\pi$-electronic compounds can be correctly interpreted by using results in [21-25]. The idea was mainly based on the fact that the linear conjugated molecules can be treated as a one-dimensional collective system. Upon the transition to the ions of conjugated systems, the positive charge (or hole) in cations or negative charge (electron) in anions is not delocalized uniformly over the whole system, but is distributed with a periodic variation of the density along the molecule [25]. The appearance of such a charge variation leads to periodic changes in the lengths of 


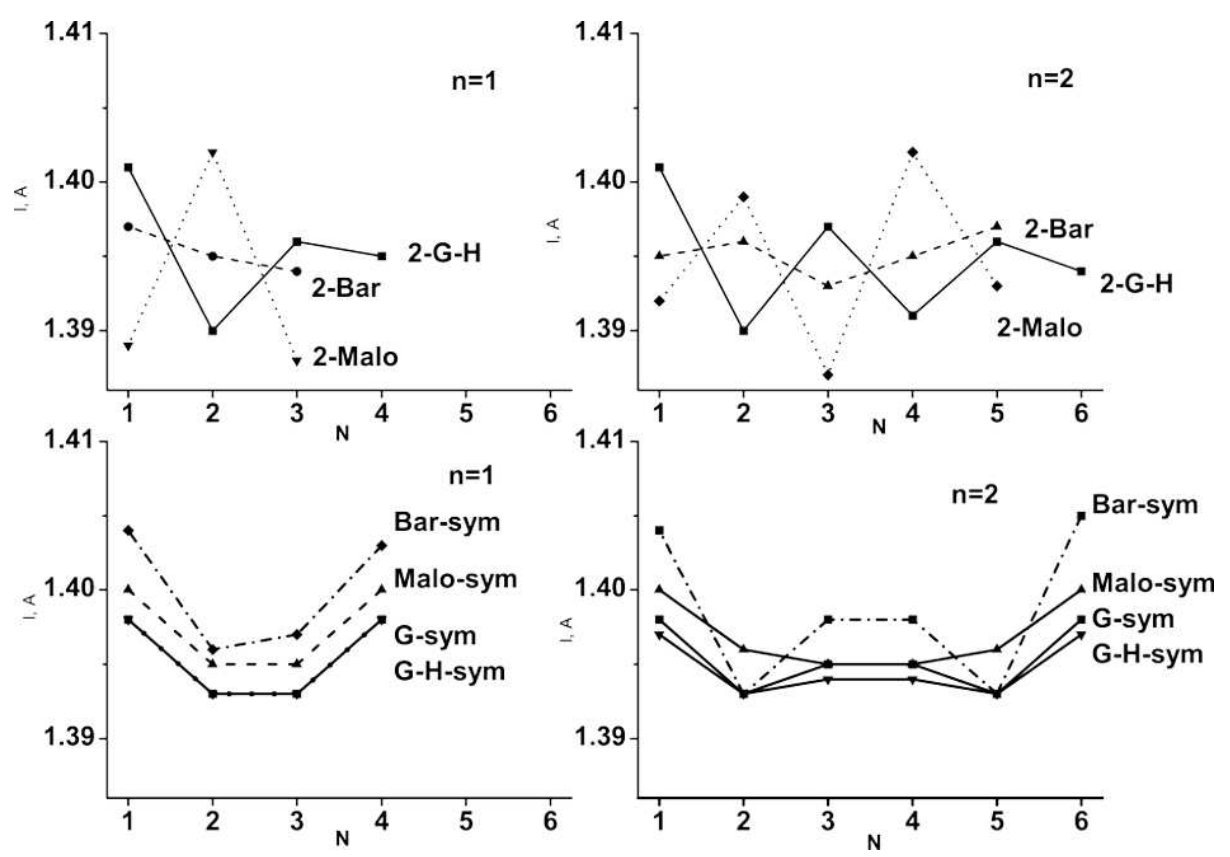

Fig. 2. Length of the bonds in the open chain of the symmetric and asymmetric dyes $\mathbf{1}, \mathbf{2}$ (See the legend in Fig. 1). $N$ - the number of a carbon atom in the polymethine chain

carbon-carbon bonds. On other hand, the appearance of the charge in the collective system of $\pi$-electrons causes the appearance of the so-called soliton level within the energy gap, as well as the simultaneous shift of the energy gap. The transition from the neutral molecule to the cation dye leads to a shift of the occupied and vacant electron levels downward compared with the corresponding levels (and the energy gap), while the levels and the energy gap shift upward in the anion dyes $[16,25]$. In our previous paper [17] concerning the symmetric anionic dyes, namely aminocoumarine derivatives, the symmetric positions of the electron levels in respect to the cationic indocyanine were shown. This paper concerns the electron structure of some other anionic dyes, first of all, the asymmetric compounds, as well as the nature of the electron transitions in them.

At the beginning, we will compare the lengths of carbon-carbon bonds and the charge distributions along the polymethine chains of the symmetric and asymmetric dyes. The calculated values are collected in Fig. 2. In all symmetric compounds, some increase of the bond lengths is obtained at the both chain ends irrespective of the number of vinylene groups $n$ in the chromophore. In the dyes with longer chain $(n=2)$, the small alternation of the lengths of the neighbour- ing bonds appears, the alternation degree depending on the acceptor strength of the terminal residues.

Going from the symmetric dyes $\mathbf{2}$ to the asymmetric derivatives $\mathbf{1}$ causes a considerable change in the equilibrium molecular geometry. The calculations give the appreciable degree of bond alternation along a chain from one terminal group to another one, except for dye 2-Bar with short chain $(n=1)$.

The charge distribution in the chain is seen from Fig. 3 to be also converted substantially, while going from the symmetric dyes $\mathbf{2}$ to the asymmetric dyes $\mathbf{1}$. The replacing of the variable terminal group influences only the extreme position (close to the variable terminal residue), while the charges at the rest atoms remain practically the same. At the same time, the charge distribution in the symmetric dyes is highly sensitive to the acceptor strength of the terminal groups. Only in dyes 2-G and 2-GH differing by the dialkyl-aminogroups in the coumarine residues, the space distributions of charges practically coincide irrespective of the length of a polymethine chain.

Now, let us consider the nature of the first and second electronic transitions. It was already shown [16] that the lower vacant levels of acceptor residues in the anionic dyes are split, and this splitting is an inverse-similar to the splitting of levels in the 

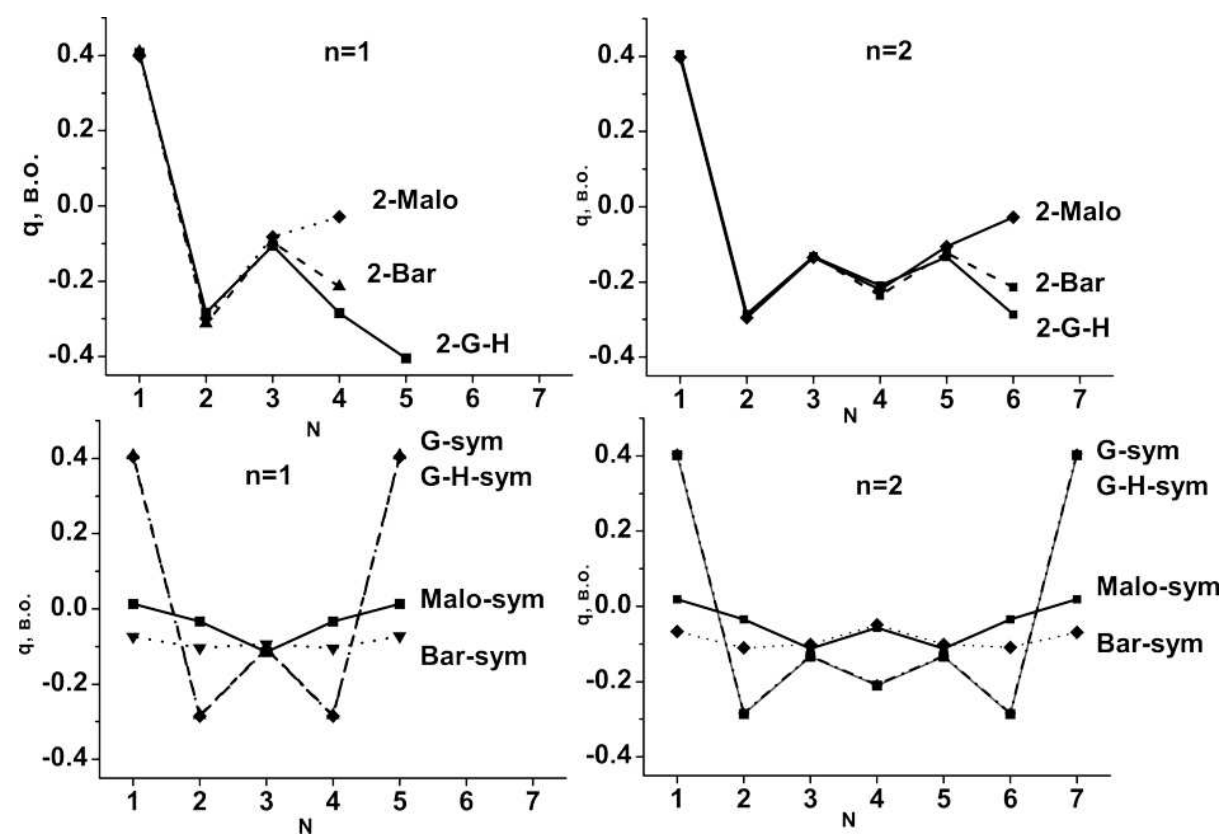

Fig. 3. Atomic charges in the open chains of the symmetric and asymmetric dyes 1, 2 (see the legend in Fig. 1). $N$ - the number of a carbon atom in the polymethine chain

cationic dyes, where two highest occupied orbitals are split. As a clear visual demonstration, Fig. 4 presents the scheme of some lowest electron transitions in the symmetric cationic dye (indocarbocyanine) (Fig. 4, b) vs anionic dye 2-G (Fig. 4, c), as well as in the polyene with the comparatible chain (Fig. 4, a).

The main distinguishing characteristic of all three cases is the nature of the second (and also the third) electron transition, whereas the first transition is described by the same single excited configuration:

$\left|S_{0} \rightarrow S_{1}\right\rangle=|\mathrm{HOMO} \rightarrow \mathrm{LUMO}\rangle$.

The higher transitions in polyene are seen from Fig. 4, a to be described by two configurations. For example, the second and third transitions are linear combinations of two configurations that involve a frontier MO and the orbital nearest to another frontier MO:

$$
\begin{aligned}
& \left(\left|S_{0} \rightarrow S_{2}\right\rangle=|\mathrm{HOMO}-1 \rightarrow \mathrm{LUMO}\rangle+\right. \\
& +\mathrm{HOMO} \rightarrow \mathrm{LUMO}+1\rangle) / \sqrt{2}, \\
& \left(\left|S_{0} \rightarrow S_{3}\right\rangle=|\mathrm{HOMO}-1 \rightarrow \mathrm{LUMO}\rangle-\right. \\
& -\mathrm{HOMO} \rightarrow \mathrm{LUMO}+1\rangle) / \sqrt{2} .
\end{aligned}
$$

In contrast to neutral polyenes, each of the higher electron transitions, $\left|S_{0} \rightarrow S_{2}\right\rangle$ and $\left|S_{0} \rightarrow S_{3}\right\rangle$ in both cationic and anionic polymethine dyes is described practically only by one single excited configuration, as one can see from Fig. 4. So, in the cationic dye, these transitions involve the same solitonic level (the lowest vacant levels) and two occupied levels (Fig. 4, b):

$$
\begin{aligned}
\left|S_{0} \rightarrow S_{2}\right\rangle & \approx|\mathrm{HOMO}-1 \rightarrow \mathrm{LUMO}\rangle, \\
\left|S_{0} \rightarrow S_{3}\right\rangle & \approx|\mathrm{HOMO}-2 \rightarrow \mathrm{LUMO}\rangle .
\end{aligned}
$$

In anionic dye $\mathbf{2 - G}$, the picture is mirror: the second and third transitions are connected with the same solitonic (but occupied) level and two next vacant levels (Fig. 4, c)

$$
\begin{aligned}
& \left|S_{0} \rightarrow S_{2}\right\rangle \approx|\mathrm{HOMO} \rightarrow \mathrm{LUMO}+1\rangle, \\
& \left|S_{0} \rightarrow S_{3}\right\rangle \approx|\mathrm{HOMO} \rightarrow \mathrm{LUMO}+2\rangle .
\end{aligned}
$$

Our study has shown that this inverse difference in the nature of the second and some higher electron transitions in the cationic (Fig. 4, b) and anionic (Fig. 4, c) polymethine dyes remains also in the asymmetric compounds. In our next discussion, we will restrict ourselves only to two lowest electron transitions, so as the first transition manifests itself in 
the absorption/fluorescence spectra as a narrow highintensity band in the visible region, while the energy of the second transition can be obtained from the fluorescence excitation anisotropy spectrum.

The measured characteristics of the spectra of symmetric and asymmetric dyes $\mathbf{1}$ and $\mathbf{2}$ are collected in Table 1.

As an illustration, the absorption, fluorescence, and fluorescence excitation anisotropy spectra of symmetric dye 2-Bar and of asymmetric dye 1-Bar are given in Fig. 5. Comparing the absorption spectra of dye 2Bar and dye 1-Bar shows that the going to the asymmetric dye causes a somewhat widening of the longwavelength band, so that the vibronic peak clearly appears on the short-wave side of the spectral band analogously to the asymmetric cationic polymethine dyes [11-15]. This peak corresponds just to the vibronic transition, not to the second electron transition, since the second transitions polarized perpendicularly is connected with the first minimum in the anisotropy spectrum: $\lambda_{2, \min }$.

The analysis of the spectral data in Table 1 shows that the distance between the absorption band maximum and the anisotropy minimum, $\Delta \lambda_{\mathrm{spl}}=\lambda_{1, \max }-$ $-\lambda_{2, \min }$, is comparatively large. This testifies to a significant interaction between acceptor levels and, thus, to a significant splitting of the first two electronic transitions. Increasing the length of the chromophore by introducing a new vinylene group causes the regular bathochromic shifts of both the long-wavelength band in the absorption spectra and the minimum in the fluorescence excitation anisotropy spectra: the socalled vinylene shift estimated by the formula [27]:

$V=\lambda(n=2)-\lambda(n=1)$.

One can see from Table 1 that the vinylene shifts for the first electron transition in symmetric anionic dyes $\mathbf{2}$ are close to $100 \mathrm{~nm}$, what was found by Koenig for the typical cationic cyanine dyes [27]. In contrast, the vinylene shifts for the second transition obtained from the anisotropy spectra are seen to be substantially less, similarly to the $S_{0} \rightarrow S_{2}$ transition in the symmetric cationic dyes, for example, indo-, thiacyanines, etc. (see, e.g., [28]).

As is seen, the fluorescence spectra from Table 1 exhibit the relative small Stokes shifts, $\Delta \nu_{S}$. This indicates directly a comparatively slight change in the equilibrium molecular geometry in the excited state upon the relaxation to the "fluorescence" or emitting

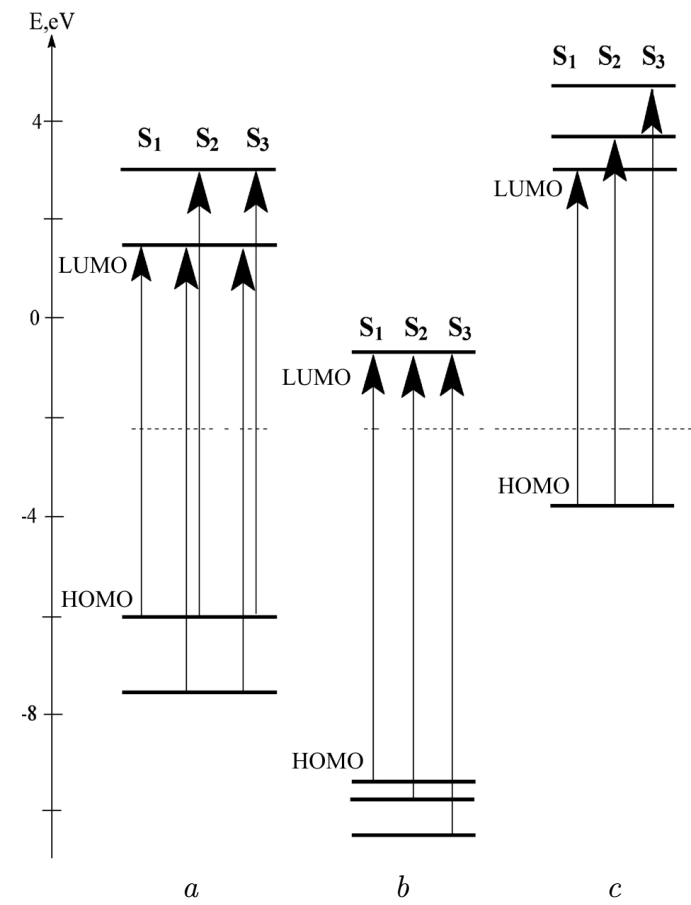

Fig. 4. Scheme of the lowest electronic transitions in neutral polyene $(a)$, cationic dye $(b)$, and anionic dye $(c)$. Schemes $(b)$ and $(c)$ are inverse for the second and third transitions

state. The values of $\Delta \nu_{S}$ in symmetric anionic dyes $\mathbf{2}$ are approximately of the same order as in symmetric cyanine dyes [28]. It should be noted that the vinylene shifts obtained from the fluorescence spectra coincide practically with these parameters for the absorption apectra obtained from the position of the long-wavelength band maximum, according to formula (8).

The performed calculations confirm the nature of the first two lowest electron transitions: both transitions are described practically by the single excited configuration: $\left|S_{0} \rightarrow S_{1}\right\rangle 0.95-0.98 \mid \mathrm{HOMO} \rightarrow$ $\rightarrow \mathrm{LUMO}\rangle$ and $\left|S_{0} \rightarrow S_{2}\right\rangle 0.85-0.95 \mid \mathrm{HOMO} \rightarrow$ $\rightarrow \mathrm{LUMO}+1\rangle$, the oscillator strength of the first transition, $f_{1}$, exceeding the value $f_{2}$ by several orders (see Table 2), which agrees with the high experimental intensity of the long-wavelength band and with the negligible absorption in the short-wavelength spectral region $(300-500 \mathrm{~nm})$. However, the comparison of Tables 1 and 2 points out that the calculated wavelengths of the both electron transitions differ significantly from the corresponding experimentally data. Unfortunately, this is the well-known typical disadvantage of the TD DFT method as for the 
Table 1. Positions of band maxima

in the absorption, fluorescence, and fluorescence excitation spectra of dyes 1 and 2

\begin{tabular}{|c|c|c|c|c|c|c|c|c|c|}
\hline \multirow{2}{*}{ Dye } & \multirow{2}{*}{$n$} & \multicolumn{2}{|c|}{ Absorption } & \multicolumn{3}{|c|}{ Fluorescence } & \multicolumn{3}{|c|}{ Anisotropy } \\
\hline & & $\lambda_{1, \max }, \mathrm{nm}$ & $V, \mathrm{~nm}$ & $\lambda_{1, \max }, \mathrm{nm}$ & $V, \mathrm{~nm}$ & $\Delta \nu_{S}, \mathrm{~cm}^{-1}$ & $\lambda_{2, \min }, \mathrm{nm}$ & $V, \mathrm{~nm}$ & $\Delta \nu_{\mathrm{spl}}, \mathrm{cm}^{-1}$ \\
\hline \multicolumn{10}{|c|}{ Symmetric dyes } \\
\hline $2-\mathrm{G}$ & 1 & 615 & & 636 & & 537 & 447 & & 6111 \\
\hline & 2 & 711 & 96 & 733 & 97 & 422 & 470 & 23 & 7212 \\
\hline 2-G-H & 1 & 572 & & 581 & & 271 & 382 & & 8695 \\
\hline & 2 & 683 & 111 & 694 & 113 & 232 & 436 & 54 & 8294 \\
\hline 2-Bar & 1 & 490 & & 518 & & 1103 & 290 & & 14075 \\
\hline \multirow{3}{*}{ 2-Malo } & 2 & 588 & 98 & 620 & 102 & 878 & 360 & 70 & 10771 \\
\hline & 1 & 445 & & 468 & & 1104 & - & & \\
\hline & 2 & 540 & 95 & 563 & 95 & 757 & 342 & & 10721 \\
\hline \multicolumn{10}{|c|}{ Asymmetric dyes } \\
\hline 1-G-H & 1 & 600 & & 623 & & 615 & 420 & & 7143 \\
\hline 1-Bar & 1 & 516 & & 536 & & 723 & 396 & & 5872 \\
\hline \multirow{3}{*}{ 1-Malo } & 2 & 606 & 90 & 627 & 91 & 553 & 433 & 37 & 6593 \\
\hline & 1 & 500 & & 512 & & 469 & 372 & & 6882 \\
\hline & 2 & 580 & 80 & 602 & 90 & 630 & 408 & 36 & 7268 \\
\hline
\end{tabular}

calculation of the electron transitions in linear polymethine cationic/anionic dyes absorbing in the visible and near IR region of the spectrum [30].

One can see that the difference in the calculated and experimental wavelengths for the first transition is substantially larger than for the second transition. As a result, the distance between the obtained $\lambda_{1, \max }$ (absorption spectrum) and $\lambda_{2, \min }$ (anisotropy spectrum) exceeds significantly the distance between the corresponding calculated values. In addition, the calculated vinylene shifts, $V$, for the first transition are less than the shifts of the position of the longwavelength band in the absorption spectra upon the passage to a higher vinylog. At the same time, the calculated parameter $V$ for the second transition is quite close to the experimental shift of the position of the minimum, $\lambda_{2, \min }$, in the fluorescence excitation anisotropy spectra.

Now, let us consider the changes in the spectral characteristics, while going to asymmetric polymethine dyes 1. It follows from Table 1 that the asymmetry is accompanied by a decrease of the vinylene shifts in the absorption spectra (detected the first electron transition), whereas the vinylene shifts in the anisotropy spectra (detected the second electron transition) of the asymmetric dyes increase somewhat.
However, the main feature of the optical spectra of the asymmetric dyes is related to the position of the band maximum in the absorption spectrum, as compared with the band maximum of the parent symmetric dyes, what is traditionally used for the quantitative estimation of the degree of asymmetry of the asymmetric cyanines. It was proposed by Brooker [11] to introduce a parameter deviation $D$, which is calculated in the following way:

$D=\left(\lambda_{\mathrm{sd} 1}+\lambda_{\mathrm{sd} 2}\right) / 2-\lambda_{\text {as }}$.

Here, $\lambda_{\text {as }}$ is the absorption maximum of the asymmetric dye, and $\lambda_{\mathrm{sd} 1}$ and $\lambda_{\mathrm{sd} 2}$ are maxima of the corresponding symmetric parent molecules.

It was found [11] that $D>0$ for the typical asymmetric cationic dyes, i.e. the positions of the maximum for the asymmetric dye, and $\lambda_{\text {as }}$ is shifted in the direction of shorter wave lengths as compared with the arithmetic mean value from the maxima of the parent dyes. The analysis of the experimental data from Table 1 shows that there are appreciable positive deviations for the both vinylogs of asymmetric dyes 1-Bar and 1-Malo, in contrast to the series of dyes $\mathbf{1 - G}-\mathbf{H}$ with the inappreciable degree of asymmetry. Moreover, the magnitude of $D$ changes gradually at the lengthening of the polymethine chain. So, 
the deviation of the long-wavelength band in the absorption spectrum of asymmetric dye 1-Bar for $n=1$ $D\left[\lambda_{1}\right]=36 \mathrm{~nm}$ increases, while passing to higher vinylog 1-Bar $(n=2): D\left[\lambda_{1}\right]=44 \mathrm{~nm}$.

Just the same increase of a deviation is observed for the dye series Malo: $D\left[\lambda_{1}\right]=30 \mathrm{~nm}(n=1)$ and $D\left[\lambda_{1}\right]=57 \mathrm{~nm}(n=2)$. This testifies to an increase of the degree of asymmetry upon the introduction of the new vinylene group into the chain. In contrast to the spectral effect of the first electron transition, the deviation of the second transition detected by the minimum in the anisotropy spectra, $D\left[\lambda_{2}\right]$ (e.g., in the asymmetric dye series 1-Bar) proves to be negative,

Table 2. Calculated characteristics of electron transitions in dyes 1 and 2

\begin{tabular}{|c|c|c|c|c|c|}
\hline Dye & $n$ & Transition & $\lambda, \mathrm{nm}$ & $f$ & $V, \mathrm{~nm}$ \\
\hline \multicolumn{6}{|c|}{ Symmetric dyes } \\
\hline \multirow[t]{4}{*}{$2-G$} & \multirow[t]{2}{*}{1} & $S_{0} \rightarrow S_{1}$ & 469 & 1.84 & \\
\hline & & $S_{0} \rightarrow S_{2}$ & 397 & 0.004 & \\
\hline & \multirow[t]{2}{*}{2} & $S_{0} \rightarrow S_{1}$ & 517 & 2.44 & 43 \\
\hline & & $S_{0} \rightarrow S_{2}$ & 428 & 0.004 & 31 \\
\hline \multirow[t]{4}{*}{ 2-G-H } & \multirow[t]{2}{*}{1} & $S_{0} \rightarrow S_{1}$ & 472 & 1.27 & \\
\hline & & $S_{0} \rightarrow S_{2}$ & 410 & 0.003 & \\
\hline & \multirow[t]{2}{*}{2} & $S_{0} \rightarrow S_{1}$ & 520 & 1.81 & 48 \\
\hline & & $S_{0} \rightarrow S_{2}$ & 445 & 0.004 & 35 \\
\hline \multirow[t]{4}{*}{ 2-Bar } & \multirow[t]{2}{*}{1} & $S_{0} \rightarrow S_{1}$ & 392 & 1.24 & \\
\hline & & $S_{0} \rightarrow S_{2}$ & 326 & 0 & \\
\hline & \multirow[t]{2}{*}{2} & $S_{0} \rightarrow S_{1}$ & 446 & 1.82 & 54 \\
\hline & & $S_{0} \rightarrow S_{2}$ & 340 & 0 & 14 \\
\hline \multirow[t]{4}{*}{ 2-Malo } & \multirow[t]{2}{*}{1} & $S_{0} \rightarrow S_{1}$ & 352 & 1.11 & \\
\hline & & $S_{0} \rightarrow S_{2}$ & 277 & 0 & \\
\hline & \multirow[t]{2}{*}{2} & $S_{0} \rightarrow S_{1}$ & 408 & 1.63 & 56 \\
\hline & & $S_{0} \rightarrow S_{2}$ & 292 & 0.01 & 15 \\
\hline \multirow{5}{*}{ 1-G-H } & & Asymme & ic dyes & & \\
\hline & \multirow[t]{2}{*}{1} & $S_{0} \rightarrow S_{1}$ & 474 & 1.45 & \\
\hline & & $S_{0} \rightarrow S_{2}$ & 403 & 0.15 & \\
\hline & \multirow[t]{2}{*}{2} & $S_{0} \rightarrow S_{1}$ & 521 & 2.04 & 47 \\
\hline & & $S_{0} \rightarrow S_{2}$ & 437 & 0.15 & 38 \\
\hline \multirow[t]{4}{*}{ 1-Bar } & \multirow[t]{2}{*}{1} & $S_{0} \rightarrow S_{1}$ & 425 & 0.88 & \\
\hline & & $S_{0} \rightarrow S_{2}$ & 348 & 0 & \\
\hline & 2 & $S_{0} \rightarrow S_{1}$ & 470 & 1.43 & 45 \\
\hline & & $S_{0} \rightarrow S_{2}$ & 386 & 0.65 & 38 \\
\hline \multirow[t]{4}{*}{ 1-Malo } & \multirow[t]{2}{*}{1} & $S_{0} \rightarrow S_{1}$ & 419 & 0.61 & \\
\hline & & $S_{0} \rightarrow S_{2}$ & 338 & 0.78 & \\
\hline & \multirow[t]{2}{*}{2} & $S_{0} \rightarrow S_{1}$ & 457 & 1.13 & 38 \\
\hline & & $S_{0} \rightarrow S_{2}$ & 378 & 0.84 & 40 \\
\hline
\end{tabular}

ISSN 2071-0194. Ukr. J. Phys. 2015. Vol. 60, No. 7
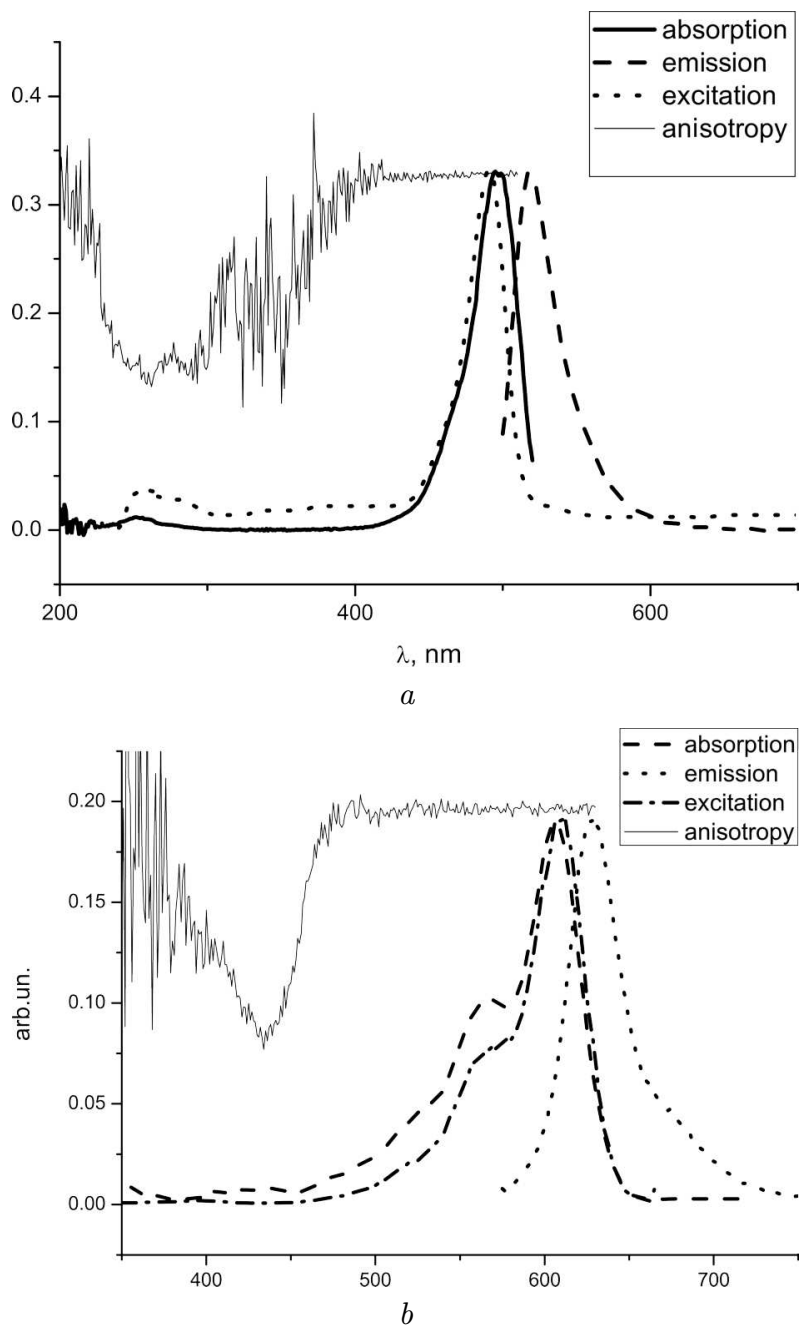

Fig. 5. Spectra of symmetric dye 2-Bar $(a)$ and asymmetric dye 1-Bar $(b)$

and the absolute value decreases, as the length of the polymethine chain increases: $D\left[\lambda_{2}\right]=-27 \mathrm{~nm}(n=$ $=1)$ and $D\left[\lambda_{1}\right]=-18 \mathrm{~nm}(n=2)$.

\section{Conclusion}

Thus, the combined spectral and quantum-chemical investigation of the specially synthesized asymmetric anionic dyes, the derivatives of aminocoumarine, as well as the corresponding symmetric dyes, has shown that the introduction of the excess electric charge in a molecule leads to a significant shift of the electron levels. The results of calculations have shown the inverse nature of the position shift of the first two electron transitions compared with cationic polymethine 
dyes. The short-wavelength shift of the first electron transition is observed in the absorption spectra of asymmetric dyes, in respect to the parent symmetric dyes. But in the fluorescence excitation anisotropy spectra, which detect the second electron transition, there is a shift in the opposite direction. It is found that the lengthening of the chromophore is accompanied by an increase of the shift magnitude of the first electron transition and, in contrast, by a decrease of the shift magnitude of the second electron transition, which indicates the increase of the electron asymmetry degree of the asymmetric anionic dye.

1. V.M. Yashchuk, V.Yu. Kudrya, I.O. Savchenko, R.D. Fedorovich, V.V. Cherepanov, O.A. Marchenko, A.G. Naumovets, V.M. Nechitaylo, L.O. Vretik, G.P. Golovach, Z.I. Kazantseva, and I.I. Dyoshin, Mol. Cryst. Liq. Cryst. 496, 39 (2008).

2. A. Mishra, Chem. Rev. 100, 1973 (2000).

3. G. Bach and S. Daehne, Cyanine Dyes and Related Compounds, edited by M. Sainsbury (Elsevier, Amsterdam, 1997), vol. IVb, Chapt. 15.

4. F. Meyers, S.R. Marder, and J.W. Perry, Introducing to the Nonlinear Optical Properties of Organic Materials (WileyVCH, Weinheim, 1998), Chapt. 6.

5. N. Tyutyulkov, J. Fabian, A. Mehlhorn, F. Dietz, and A. Tadjer, Polymethine Dyes. Structure and Properties (St. Kliment Ohridski Univ. Press, Sofia, 1991).

6. S. Daehne, Science 199, (1978).

7. H. Kuhn, J. Chem. Phys. 17, 1098 (1949).

8. J. Fabian, J. Molec. Struct. 766, 49 (2006).

9. A.D. Kachkovskii, O.V. Przhonska, and A.B. Ryabitzki, J. Molec. Struct. 802, 75 (2007).

10. F.M. Hamer, Cyanine Dyes and Related Compounds (Interscience, New York, 1964).

11. L. Brooker, Rev. Mod. Phys. 14, 275 (1942).

12. A.D. Kachkovsky, Uspekhi Khim. 66, 715 (1997).

13. A.V. Stanova, A.B. Ryabitsky, V.M. Yashchuk, O.D. Kachkovsky, A.O. Gerasov, Ya.O. Prostota, and O.V. Kropachev, J. Molec. Struct. 988, 102 (2011).

14. Ju. Bricks, A. Ryabitskii, and A. Kachkovskii, Eur. J. Org. Chem. 22, 3439 (2009).

15. Ju. Bricks, A. Ryabitskii, and A. Kachkovskii, Eur. J. Chem. 16/29, 8773 (2010).

16. A.O. Gerasov, M.P. Shandura, Yu.P. Kovtun, and O.D. Kachkovsky, J. Phys. Org. Chem. 21, 419 (2008).

17. L.A. Padilha, S. Webster, O.V. Przhonska, H. Hu, D. Peceli, T.R. Ensley, M.V. Bondar, A.O. Gerasov, Yu. P. Kovtun, M.P. Shandura, A.D. Kachkovski, D.J. Hagan, and E.W. Van Stryland, J. Phys. Chem. A 114, 6493 (2010).

18. A.O. Gerasov, M.P. Shandura, and Yu.P. Kovtun, Dyes Pigm. 79, 252 (2008).

19. J.R. Lacowicz, Principles of Fluorescence Spectroscopy (Plenum Press, New York, 1983).
20. M.J. Frisch, G.W. Trucks, H.B. Schlegel et al., GAUSSIAN03; revision B.05 (Gaussian, Pittsburgh, PA, 2003).

21. J.L. Bredas and G.B. Street, Acc. Chem. Res. 18, 309 (1985).

22. J.L. Bredas, D. Belionne, J. Cornil, J.Ph. Calhert, Z. Shuai, and R. Silbey, Synth. Metals 125, 107 (2002).

23. A. Yu, C. Tolbert, D. Farrow, and D. Joneas, J. Phys. Chem. A 106, 9407 (2002).

24. T. Giamarchi, Chem. Rev. 104, 5037 (2004).

25. A.D. Kachkovsky, Theor. Exp. Chem. 41, 139 (2005).

26. M.J.S. Dewar, The Molecular Orbital Theory of Organic Chemistry (McGraw-Hill, New York, 1969).

27. W. Koenig, J. Prakt. Chem. 112, 1 (1925).

28. O.V. Przhonska, S. Webster, L.A. Padilha, H. Hu, A.D. Kachkovski, D.J. Hagan, and E.W. Van, in: Advanced Fluorescence Reporters in Chemistry and Biology I (Springer, Berlin, 2010).

29. A.A. Ishchenko, Uspekhi Khim. 60, 865 (1991).

30. J. Fabian, Dyes Pigm. 84, 36 (2010).

Received 01.12.14

В.І. Борисюк, В.М. Ящук, А.П. Науменко,

А.В. Станова, В.Г. Герасъова, А.О. Герасъов,

Ю.П. Ковтун, М.П. Шандура, О.Д. Качковсъкий

ВПЛИВ НАДЛИШКОВОГО

ВІД'ЄМНОГО ЗАРЯДУ НА СПЕКТРИ

ПОГЛИНАННЯ ТА АНІЗОТРОПІЇ ЗБУДЖЕННЯ

ФЛЮОРЕСЦЕНЦІЇ НЕСИМЕТРИЧНИХ

ПОЛІМЕТИНОВИХ БАРВНИКІВ

Р е з ю м е

Робота присвячена спектрально-люмінесцентному та квантово-хімічному дослідженню вінілогічних серій несиметричних аніонних поліметинових барвників, похідних амінокумарину, а також відповідних симетричних барвників. Особлива увага приділена спектральним проявам внесення надлишкового електричного заряду в молекули несиметричних аніонних поліметинових барвників. Показано, що введення заряду до несиметричного барвника даного типу спричинює істотне зміщення енергетичних електронних рівнів. Розрахунки також показали інверсний характер зміщення перших двох електронних переходів в аніонних та відповідних катіонних барвниках. Встановлено, що спектрально ефект асиметрії проявляється як зсув першого електронного переходу в спектрах поглинання у короткохвильовий діапазон спектра і як зсув другого переходу в спектрах анізотропії збудження флюоресценції у довгохвильовий діапазон порівняно із середньоарифметичною величиною максимумів поглинання відповідних материнських барвників. Знайдено, що подовження хромофора супроводжується зростанням величини цього зсуву i, навпаки, його зменшенням для другого переходу. Отримані в роботі результати можуть бути використані в дизайні молекулярних систем із заданою вольт-амперною характеристикою для наноелектроніки. 